\title{
Gender Discrimination Survey in the STEM Field: a Case Study of Korean Science High Schools
}

Ju Young Lee

Max Planck Institute for Biological Cybernetics

\begin{abstract}
We conducted an online survey on gender discrimination in the Korean science, technology, engineering, and mathematics (STEM) community. Over 150 respondents voluntarily participated in the survey. The majority of the responses described how women were being discriminated against. Twelve female students reported their experiences in science high schools. These cases included sexual objectification, stereotyping and exclusion.
\end{abstract}

\section{INTRODUCTION}

There was a revivial of Korean online feminism in 2015 when the hashtag movement called “\#나는_페미니스트입니다" (\#I_am_a_feminist) was initiated. The following year, a series of hashtag movements "\#O 0 계_내_성 폭력” (\#Sexual_violence_within_XX) exposed incidents from different fields, including literature, sports, art, film, religion, and social activism. As women realized that their experiences were universal, they built solidarities and continued to produce testimonies. In 2017, we initiated an online survey to collect incident reports of gender discrimination in the science, technology, engineering, and mathematics (STEM) community.

We were four graduate students, two women and two men, studying different subjects in the STEM field. Our aim was to record cases of gender discrimination in the STEM field and to raise awareness of the issue. We hoped that the victims would no longer trivialize their experiences or blame themselves, recognize the issue as a structural problem, and gain the courage to share their stories. As the project grew larger and more successful, we handed it over to “페미회로” (Femicircuit), a union of feminists from science and technology-oriented universities in Korea. The initial members remained as advisors. 


\section{METHOD}

We took an online crowdsourced survey called “서양에서 동양인으로서 경험하는 차별 아카이빙" (Archiving the stories of discrimination against Asian people in Western countries) ${ }^{1}$ as a reference when designing this survey. Our survey was created using "Google Forms", a free online app. The survey consisted of three parts: an explanation of the project, a consent form, and the questionnaires. The first part introduced the organizers and explained the purpose of our project. Through the consent form, the respondents could elect whether their answers could be published openly online. Furthermore, they were asked if a third party could modify their answers and publish them in other formats (for example, as a novel). In the questionnaires, the participants were asked to provide their gender; the number of perpetrators; the gender of the perpetrators; the time and the place of the incident; and a detailed description of the incident. The questions were open-ended rather than in multiple-choice format. All responses, that the participants agree could be published online, are available at the following link: bit.ly/STEMGenderEquality.

In order to recruit participants, we contacted student groups with an interest in students' rights or feminism. We introduced the project and asked them to distribute the survey link using their platform (e.g. a university's own online platform). We established a database of contact information including student councils and feminist study groups from four universities that specialize in science and technology (Daegu Gyeongbuk Institute of Science and Technology, Korea Advanced Institute of Science and Technology, Pohang University of Science and Technology, Ulsan National Institute of Science and Technology) and feminist groups from universities throughout Korea (31 student clubs from 21 universities).

1 The survey was part of a project called "I am angry!," which was supported by the Federal Ministry of Education and Research of Germany. They collected 294 stories of discrimination against Asians living in "the Western world". The entries are available at: http://iamangry.de/ 
Figure 1. This is an example of the weekly post where we shared some of the new entries from the previous week.

이번 주 제보에는 노골적인 성적 대상화 사례와 과학고 남톡방 애기도 있습니다.

사례 제보: bit.ly/stemgenderequality

사례 열람: bit.ly/STEMGenderEquality

문의: stemgenderequality@gmail.com

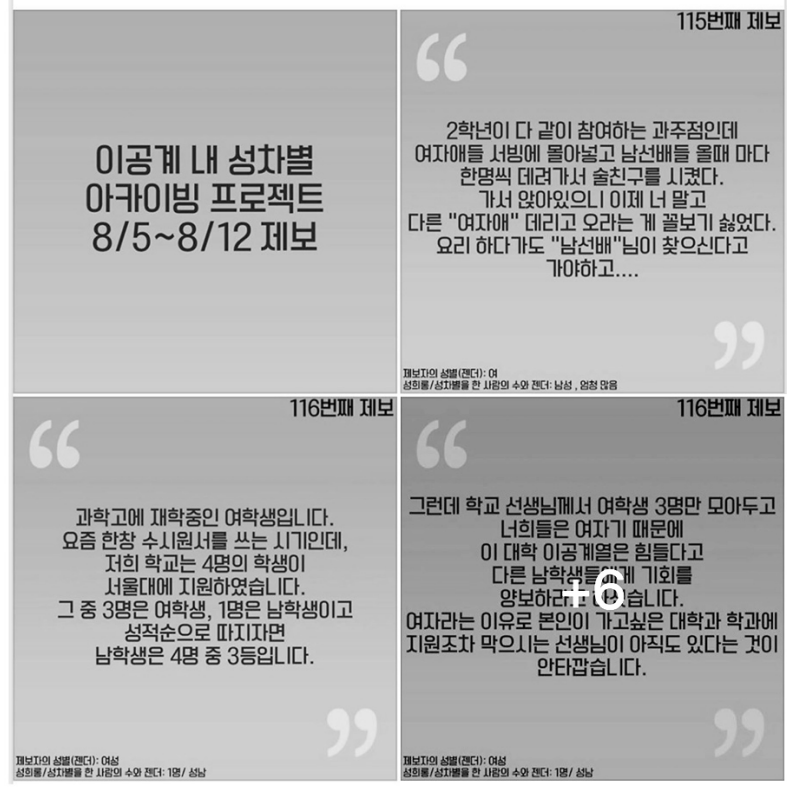

We managed publicity using our own Facebook page called "이공계 내 성 차별 아카이빙 프로젝트" (The archive of gender discrimination in the STEM field) and by collaborating with a podcast called "과학기술정책 읽 어주는 남자들” (Science Technology Policy Readers). The Facebook page was the main platform on which we updated our progress and shared news. During the first two months, we regularly posted examples of survey responses (see Figure 1). The hosts of the podcast "Science Technology Policy Readers" were supportive of the project from the brainstorming phase of the project. The podcast released three episodes based on the survey responses and one episode in which two members of our team were interviewed. 


\section{RESULTS}

From May 2017 to July 2019, 154 responses had been collected. After excluding duplicates and incomplete responses, there were 150 valid responses. Among the valid responses, $138(92.0 \%)$ were from female respondents and $11(7.3 \%)$ were from male respondents. In 144 (96\%) cases, women were the victims of discrimination. This illustrates that many women in the STEM field experience gender discrimination.

Figure 2. The distribution of the online survey entries according to the academic level of the victims. The graph includes only the entries with information about the respondents' academic status.

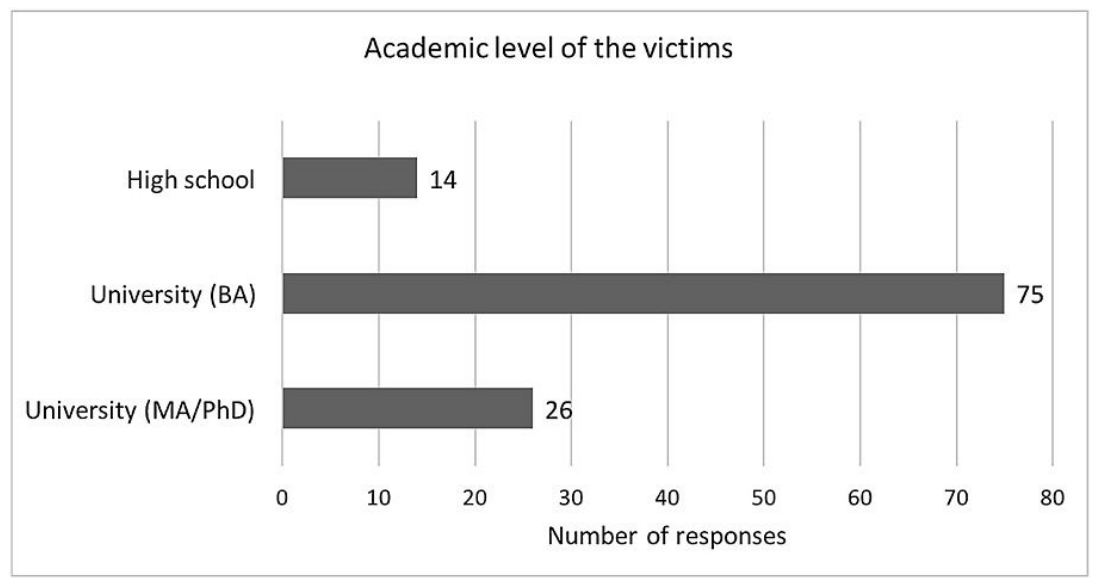

Figure 2 shows the categorization of entries according to the victim's academic status. We were surprised to receive reports from people at a stage as early as high school. In this paper, I will focus on science high schools, from which 12 out of 14 of the high school cases were reported. These 12 cases were reports from female students describing there experiences of sexual objectification, stereotyping and exclusion. 
Sexual objectification is an act of objectifying women as mere sexual beings. For example, respondent number 10 wrote:

"When we first came to the school, female students' appearance was rated, including rating who has the best body shape, breasts, and legs... Similarly, I found out that, in their dorms, male students talked about what girls wore and how their breasts looked bigger on some days than others and maybe that's because they wore a padded bra."

Similar experiences of rating female students' faces and bodies were reported in three other responses. Other cases of sexual objectification included secretly taking pictures of female students when they were dancing (response 73), brazenly staring at female students' body parts and talking about them (responses 73, 91). According to responses 74 and 83, some schools responded with stricter dress codes for female students. Nonetheless, "there were always boys who would talk about breast size. (respondent 74)".

\section{STEREOTYPING}

Several responses revealed difficulties in facing stereotypes associated with female gender. For instance, respondent 73 wrote:

"These comments from teachers and classmates were here, there and everywhere. Compared to male students, female students are worse at mathematics, worse at spatial perception, worse at physics, girls can stay up all night studying and memorize biology textbooks by heart but boys can't do that, girls are [inherently] good at English so they are privileged because they can read an English textbook faster (people never acknowledged that being good at English or sleeping less to study also requires hard work and competence)."

It is a common stereotype that women do not perform as well in mathematics, spatial perception and physics. Although there have been multiple scientific studies that have disproven any inherent gender gap in these subjects, the stereotype continues to survive within and beyond the scientific community. Other stereotypes were that: female students "tend to divide into groups and create conflicts (response 73)", "women don't have the physical strength required for engineering (response 101)", "majoring in science at Seoul National University will be difficult" for women (response 
116), "it's okay for girls to study less because they can get married (response 129)" and girls are more attentive and refined whereas boys are naturally clumsy (entry 142).

\section{EXCLUSION}

Historically, women have been excluded from many opportunities and science education was not an exception. Science high schools in Korea only started accepting female students in $1988 .^{2}$ Since then, the number of female students in science high schools has risen to approximately $20 \%$. However, female students still face exclusion. For example, respondent 73 wrote:

"Since the number of female students is so much smaller, groups are usually made up of one female and three or four male students for group projects. When a female student creates a group chat to ask when to meet, male students just read and do not reply [to messages]. Then they finish the assignment on their own without taking the female student into consideration and hand in the assignment without her name."

The form in which female students were excluded varied. Some serious incidents were perpetrated by male students (responses 73, 96), but more were committed by adults, including parents of male students (responses $74,129,135)$ and a schoolteacher (response 116). The justifications were also different. Some male students justified their actions with the belief that female students "have relatively lower grades and are not strong minded"(response 96). Parents of male students worried that their sons would be distracted from their studies by the presence of females (responses 74, 135). One teacher tried to stop female students from applying for a science major in a highly competitive university, reasoning that it would be too difficult for them (response 116).

\section{DISCUSSION}

Although this paper focused on Korean science high schools, a similar pattern of discrimination against women continues throughout their academ- 
ic careers ${ }^{3}$ and extends beyond Korea. ${ }^{4}$ Dr Karen Kelsky conducted an online survey called "Sexual Harassment in the Academy: A Crowdsource Survey" ${ }^{5}$ which revealed that many incidents took place in the STEM field across the world. Prejudice questioning women's ability to study or conduct science also prevails globally. Although systematic studies have shown that there is no scientific evidence to support these stereotypes, ${ }^{6}$ some scientists openly support such claims. ${ }^{7}$ Lastly, testimonials from many female scientists have exposed experiences with implicit and explicit exclusion in the STEM field. ${ }^{8}$

Gender discrimination in the Korean STEM community was not discussed openly and individual incidents were treated as personal problems. However, our survey revealed that similar cases have happened across different institutes. Repeated reports prove that the problem is structural rather than personal. We hope that open access to the survey will allow people to see for themselves how prevalent gender discrimination is in the STEM field and lead to discussions that improve the situation.

\section{REFERENCES}

Castelvecchi, Davide. (2018, October 1) CERN suspends physicist over remarks on gender bias. Nature. Retrieved May 20, 2020, from https://www.nature.com/articles/d41586-018-06913-0\#: :text=Davide\%20Castelvecchi\&text=Europe's \%20leading\%20particle\%2D physics\%20laboratory,a\%20presentation\%20at $\% 20$ the\%20lab.

Fine, Cordelia. (2010). Delusions of gender: How our minds, society, and neurosexism create difference. W.W. Norton \& Company.

Hill, Catherine, Christianne Corbett, and Andresse St Rose. (2010). Why so few? Women in science, technology, engineering, and mathematics. American Association of University Women.

Kelsky, Karen. (2017, December 1). A Crowdsourced Survey of Sexual Harassment in the Academy. The Professor Is In. Retrieved May 20, 2020, from https://theprofessorisin.com/2017/12/01/a-crowdsourced-survey-of-sexual-harassment-in-theacademy/

3 Oh, 2017; Kim, 2017.

4 Hill/Corbett/St Rose, 2010; Libarkin, accessed: 2019.

5 Kelsky, accessed: 2019.

6 Lindberg/Hyde/Petersen/Linn, 2010; Fine, 2010.

7 Castelvecchi, 2018.

8 Margolis/Fisher, 2015. 
Kim, Jung Hyun. (2017, November 19) 김정현. [Gihoeg / Yeoseong-yeonguja gyeonglyeogdanjeol, daehag-eun - jung] Yeoseong mil-eonaego chabyeolhaneun yeongusil, boiji anhneun milae [[기획/ 여성연구자 경력단절, 대학은 - 中] 여성 밀어내고 차 별하는 연구실, 보이지 않는 미래 [Focus / Career break of female researchers, university - second series] A laboratory that discriminates and discriminates women, the invisible future] University News Network 한국대학신문.

Libarkin, Julie. (2019). Academic Sexual Misconduct Database. Retrieved May 20, 2020, from https://academic-sexual-misconduct-database.org/

Lindberg, Sara M., Janet S. Hyde, Jennifer L. Petersen, and Marcia C. Linn. (2010). New trends in gender and mathematics performance: a meta-analysis. Psychological Bulletin 136(6), 1123-1135.

Margolis, Jane L., and Allan L. Fisher. (2002). Unlocking the Clubhouse: Women in Computing. MIT Press.

Oh, Cheol Woo. (2017, August 17) 오철우. Seongpyeongdeung-i gwahag baljeon mitdol" igong-gyee peminijeum balam 성평등이 과학 발전 밑돌” 이공계에 페미니즘 바람 [Gender equality is the foundation of scientific development. Feminism wave in science and engineering world] The Hankyoreh 한겨례.

Pollack, Eileen. (2015). The Only Woman in the Room: Why Science Is Still a Boys' Club. Beacon Press.

Yoon, Jung-Ro. (2016). 윤정로. Sahoe Sog-ui Gwahaggisul 사회 속의 과학기술 [Science and Technology in Society]. Sechang Publication.

\section{APPENDIX}

Here are the translated versions of 12 responses from female Science High School students, originally written in Korean. The translation was edited by Lana Balorda from the University of Tübingen. To prevent losing the implied message, we used brackets to complement the direct translation. Due to change of consent form, entry 10, 73, 74 may not be modified for redistribution by a third party.

Case number: 10

Gender of the subject: female

Number and gender of the offender(s): male community

Date and time: I don't know for sure

Place where the incident occurred: male dormitory

Explanation of the incident:

I graduated from a science high school, which had a high proportion of male students. I heard so many stories when I was attending the science high school, but I will select the ones that wouldn't identify me and my friends. 
When we first came to the school, female students' appearance was rated, including rating who has the best body shape, breasts, and legs. I couldn't figure out who made the list because it was kept secret as an act of "loyalty." It was terrible to imagine that people who are friendly to me are evaluating my body behind my back. Similarly, I found out that in their dorms male students talked about what girls wore and how their breasts looked bigger on some days than the others and maybe that's because they wore a padded bra.

When a boy broke up with his girlfriend, he told people about sexual stuff and what the ex-girlfriend did wrong. As a result, the girlfriend went through a lot of hardship. This happened because the boy was a bad person but also since the boys outnumbered the girls so much at the high school so when a false rumor spread, it was difficult for the girl to explain or be aware of all of the rumors. She got a bad reputation.

\section{Case number: 73}

Gender of the subject: female

Number and gender of the offender(s): several males

Date and time: 2013-2015

Place where the incident occurred: classroom, dormitory, online etc.

Explanation of the incident:

1. In our high school, there was a greeting event for new students. 15 senior students and 15 junior students would form one team and pick a student from the first year through playing games. The first-year student who got picked had to give some kind of performance to entertain everybody. When the student hesitated, the senior students would decide what they had to perform. For the female students including me, they made us lie on the ground and imitate a mop or imitate a window that is minutely trembling with our bodies. When someone refused, they were blamed for acting like a prude or told that they shouldn't refuse to take part and that they were ruining the atmosphere.

2. There was a Facebook page where people could report incidents anonymously (the page is deleted now). Our school had a much higher male to female ratio. When I went to the cafeteria, library, or classroom while wearing shorts, boys would whisper and stare which was humiliating to me. I reported this on the Facebook page that I wished that boys wouldn't blatantly stare or whisper when girls wear shorts. There were many hateful comments on the post including: "Why are we not allowed to look?", "It's not because we admire you. Don't delude yourself", and "We were insulting you when we were whispering. Don't 
worry." Someone also commented that girls didn't come to this school for boys to enjoy looking at them, to which others replied: "We want to look at pretty girls," and "Girls also like looking at handsome guys" and so on.

3. Male students' group chat

There is a dance club at our high school. Some male students secretly take pictures of female students when they are practicing (pictures of the dancing girls included those taken slyly from below). They would make a separate group chat only including male members and share these photos to entertain themselves. This happened during class hours. There were female teachers and students in the same place and they were proudly sharing pictures that were taken without permission.

In addition, there was an app developed by a senior student that could access student ID pictures. Male students would have fun taking female students' pictures from the app and editing them onto game characters' bodies, other male student's bodies, and dirty [sexual] pictures.

4. Annual official event actually used to rate female students Our school had dormitories. There was an annual meeting between the seniors and new students living in the same dormitory. During this meeting, the senior students would go into the first-year male students' room and ask them to pick three female students they think look the prettiest and would like to date. They would count the votes and broadcast it to the female dormitory, explaining how many votes they got for their body parts (including breasts and legs). They must have thought that they had the right to objectify and evaluate female students.

5. Casual sexist comments: These comments from teachers and classmates were here, there, and everywhere. Compared to male students, female students are worse at math, worse at spatial perception, worse at physics, girls can stay up all night studying and memorize biology text books by heart but boys can't do that, girls are [inherently] good at English so they are privileged because they can read an English text book faster (people never acknowledged that being good at English or sleeping less to study also requires hard work and competence).

Furthermore, an English teacher seemed to show more concern for female students who are such a small minority and are often excluded. Whenever this happened, students would leave multiple comments in the feedback box that the English teacher favors female students and discriminates against male students.

6. Some teachers and parents said that the school admits fewer female students because they tend to divide into groups and create conflicts and have problems living in dormitories. If I were to use the same logic, 
fewer male students should be admitted because physically violent incidents often occur in the male students' dormitory.

7. Since the number of female students is so much smaller, groups are usually made up of one female and three or four male students for group projects. When a female student creates a group chat to ask when to meet, male students just read and do not reply [to messages]. Then they finish the assignment on their own without taking into consideration the female student and hand in the assignment without her name. This was not a one-time thing but occurred often. It was the same for club activities.

All of the above are from one school. The tone of the writing may be a bit emotional as I became agitated. I wouldn't have shared these experiences if it wasn't for this database project. Thank you.

\section{Case number: 74}

Gender of the subject: female

Number and gender of the offender(s): several males and females

Date and time: during high school years

Place where the incident occurred: school

Explanation of the incident:

I also attended a science high school. I was once prohibited from joining a private tutoring group because I was a girl. The parents said that they were worried that their sons would be distracted and not be able to concentrate on studying if there was a girl in the group. Also, the school had strict dress codes for female students fearing that the boys would get distracted or sexually aroused. However, there were always boys who would talk about breast size.

\section{Case number: 83}

Gender of the subject: female

Number and gender of the offender(s): several males

Date and time: during high school years

Place where the incident occurred: high school

Explanation of the incident:

Our school didn't allow female students to wear shorts. The reason being that boys would make fun of female students' legs (???)

I was the only student in the class preparing for Physics Olympiad [International Physics Competition for High School students]. During break times, male students would tell dirty jokes, even when I was there. I was always annoyed and decided to put earphones on and put my head down on the 
desk. I overheard them saying "Hey, what if she can hear us?", so they knew that it was inappropriate.

Male senior students messed around by labeling female students with the colors of the rainbow, red being pretty and purple being ugly. When female senior students criticized them, they said they were being [overly] sensitive.

My male classmates played a game where they would name their favorite girl every night. When the exam results were out, they would figure out the position of the female students in the ranking system by sharing their own ranks (this was only possible because girls make up less than $25 \%$ of all students). ${ }^{9}$

They would start rumors that a female teacher and a male student were in love. In retrospect, it was a total lie. Sexually offensive rumors were also spread about teachers.

Case number: 91

Gender of the subject: female

Number and gender of the offender(s): male

Date and time: one morning in 2015

Place where the incident occurred: Science High School

Explanation of the incident:

Every morning, we had to go to the cafeteria or the assembly hall for the roll call. Students were mostly in their pajamas. Me and my friend also went in our pajamas. Male students talked behind us trying to guess whether we were wearing bras, talking about breast size, saying they were getting aroused. After that, I couldn't go to the roll call in pajamas again.

Case number: 92

Gender of the subject: female

Number and gender of the offender(s): male community

Date and time: fall (year not reported)

Place where the incident occurred: Science High School

Explanation of the incident:

Someone spread a rumor about seeing me and my boyfriend having sex. I had never had sex then. In those days, my boyfriend wanted to have sex

9 After every examination period, students receive a breakdown of the points that they earn for each class, along with their rank in the class. By comparing the ranks they occupied with each other, the boys could figure out which ranks were missing, and therefore belonged to the girls. Knowing the past performance of the girls in the class, the boys could then guess which rank each girl occupied. 
and kept demanding sex even though I didn't want to. So I was emotionally hurt. My boyfriend was one year above me and the person who started the rumor was as well. Therefore, there was no way that I could be aware of the rumor nor stop it. This kind of gossip is shared only between the boys. I didn't know until my boyfriend warned me that this rumor was going around and that I should be careful. The school was so small and the rumor spread to my classmates within two days. In that semester, I developed sociophobia and couldn't make eye contact with the male students. I was so distressed by the thought that male students would think about the rumor whenever they saw me. However, I never had a chance to explain and stop the rumor. Even though I didn't do anything wrong...

\section{Case number: 96}

Gender of the subject: female

Number and gender of the offender(s): several males

Date and time: during high school years

Place where the incident occurred: within school

Explanation of the incident:

In Science High Schools, there are several times more male students than female students. Female students are ignored when they try to speak and insulted publicly when included in a group for a course project. The reasons behind this behavior are that female students are believed to have relatively lower grades and are not strong minded. Male students would make sexually offensive comments and laugh in front of the victim. On the other hand, whenever there is a female face on the TV, they go crazy. They always make comments about how they look.

\section{Case number: 101}

\section{Gender of the subject: female}

Number and gender of the offender(s): relatives including men and women

Date and time: during holidays

Place where the incident occurred:

Explanation of the incident:

Hello. I am an ordinary girl attending a Science High School. Until I was in middle school, my relatives never cared about me even though I was really good at school. They only cared about my older, male cousin. When I got admitted to Science High School, they suddenly paid attention to me and told me what to do. Their advice was: women don't have the physical strength required for engineering, girls shouldn't study engineering, the best thing to do is to be a doctor or a teacher and meet a good husband 
and have kids and to lead a happy life. They say these things to me and my parents. They didn't help me when I was preparing for Science High School admission at all. I don't get why they suddenly care about my life. Once, I told my uncle that I will not get married and he shouted back saying that it is insane. Spending time with relatives every holiday is so uncomfortable...

Case number: 116

Gender of the subject: female

Number and gender of the offender(s): male

Date and time: last week

Place where the incident occurred: teachers' room

Explanation of the incident:

I am currently attending a science high school. It is currently college application season. In our school, four students applied to Seoul National University (SNU). Out of the four, three are female students and one is a male student. The male student is ranked third out of the four. However, a schoolteacher just called the three female students together and said that majoring science in SNU will be difficult for us because we are women. The teacher asked us to give up the chance [to apply to SNU] so that male students could apply. It is a pity that there are still teachers that stop students from applying to a university and a major that they want just because they are female.

Case number: 129

Gender of the subject: female

Number and gender of the offender(s): several people

Date and time: during high school years

Place where the incident occurred: unspecific location

Explanation of the incident:

Adults and private tutors often said to science high school students "It's okay for girls to study less because they can get married, but men need to take care of their family so they must go to good universities" all the time. When female students don't get good grades in a test, the parents of the male students would proudly say that "girls just can't do as well as boys," "As expected, Science High School is a boy's school". The parents were all women. 
Case number: 135

Gender of the subject: female

Number and gender of the offender(s): several people

Date and time: 2012

Place where the incident occurred: Science High School

Explanation of the incident:

In the morning, all male and female students gather in one place for the roll call. I found out that parents made complaints about female students coming to the roll call in shorts. The parents were worried that the male students would not be able to concentrate on studying because they would get aroused. The parents wanted a separate roll call for males/females or to set a dress code for the female students.

\section{Case number: 142}

Gender of the subject: female

Number and gender of the offender(s): senior student

Date and time: 3 years ago [2015]

Place where the incident occurred: school

Explanation of the incident:

When I was a first-year student in a science high school, there was an event where student clubs presented their investigations to students from other clubs and external guests. In our club, the first-year students mainly carried out the hands-on work and the second-year students instructed the firstyears. As it was the first time the event was being held, the seniors and first-years were both confused. The seniors had to stay until late to fix our mistakes. During the first meeting after this event, the leader of our club discussed how we could improve and told us to get some rest after the big event. The first-year female students were called into a separate room. The leader told us how disappointed he was. He said that boys are naturally clumsy but you girls should've prepared more delicately. He blamed us for the work that the seniors had to do afterwards. He said he was worried about how we would lead the new students next year. At that time, I didn't have the chance to think about how this was wrong because I got scared because of the scolding (though it wasn't a serious scolding). Now that some time has passed, even though it is true that the seniors had to work a lot due to our mistakes, that was a mistake that all of the first years made and it wasn't right to scold the girls more. 


\section{ABOUT THE AUTHOR}

\section{Ju Young Lee}

Ju Young Lee studied Biology at Korea University (BA) and Neuroscience at the University of Tübingen (MA). She is currently a PhD student at the Max Planck Institute for Biological Cybernetics and is investigating the human brain using medical imaging technologies such as ultra-high field magnetic resonance imaging and micro-computed tomography. The main topics for her $\mathrm{PhD}$ project include neuroscience, biomedical imaging and image processing. In addition to her main topics, she maintains an interest in the philosophy of science, and science and technology studies (STS). This article was developed based on an assignment for a course from the Department of Social and Cultural Anthropology at the University of Tübingen, called "Gender and STS".

\section{ABOUT THE INSTITUTE}

Max Planck Institute for Biological Cybernetics, Tübingen, Biomedical section/ High-field Magnetic Resonance

The project described in the article started during Ju Young Lee's master studies, independently of the University of Tübingen and the Max Planck Institute. It is a voluntary task to raise awareness of the difficulties that women in science, technology, engineering, and mathematics (STEM) experience. As an initiator of the project, she organized a team of four graduate students for the project. In addition, the podcast "과학기술정책 읽어 주는 남자들” [Science Technology Policy Readers] helped organize and publicize the project. The results of the project may be used as a reference for educators, policy makers, scientists and anyone interested in improving the gender imbalance in the STEM field. 